\title{
Adrenocortical and Behavioral Predictors of Immune Responses to Starting School ${ }^{1}$
}

\author{
W. THOMAS BOYCE, SALLY ADAMS, JEANNE M. TSCHANN, FRANCES COHEN, \\ DIANE WARA, AND MEGAN R. GUNNAR \\ Division of Behavioral and Developmental Pediatrics [W.T.B., S.A., J.M.T.], Health Psychology Program, \\ Department of Psychiatry [F.C.], Division of Pediatric Immunology and Rheumatology [D.W.], \\ University of California, San Francisco, California, and Institute for Child Development [M.R.G.], \\ University of Minnesota, Minneapolis, Minnesota
} \begin{abstract}
ABsociations between major psychologic stressors and immune
function have been documented in previous research, but few tive stressors. This study examined adrenocortical and behavioral predictors of immune responses to starting kindergarten in 39 five-year-old children, who completed laboratory visits for venipunctures $1 \mathrm{wk}$ before (time 1) and $1 \mathrm{wk}$ after (time 2) school entry. At time 1, children were also immunized with pneumococcal vaccine. Immune responses were measured as change scores for $\mathrm{T}$ $\left(\mathrm{CD}^{+}\right.$and $\left.\mathrm{CD} 8^{+}\right)$cells, B (CD19 $\left.{ }^{+}\right)$cells, lymphoproliferative responses to pokeweed mitogen (PWM), and type-specific pneumococcal antibody responses (ABR). Adrenocortical response was assessed as the change in salivary cortisol level, and behavioral difficulty with school adjustment was scored using parental ratings of behavior problems, stress due to changes in routines, and degree of adaptive challenge. Salivary cortisol rose after kindergarten entry (means $=0.39 \pm 0.28$ to $0.49 \pm 0.36 \mu \mathrm{g} / \mathrm{dL}, p=0.03$ ) and was unrelated to behavioral difficulties. $\mathrm{CD}^{+}$cells increased in number, whereas PWM declined, and $\mathrm{CD} 19^{+}$cells showed a borderline increase. Change in salivary cortisol was positively associated with change in $\mathrm{CD}_{1} 9^{+}\left(\Delta \mathrm{CD} 19^{+}\right)$and inversely related to ABR. Scores for behavioral difficulty were inversely associated with $\Delta \mathrm{CD} 4^{+}$and
\end{abstract}

Among the most striking and reliable epidemiologic features of disease in childhood populations is the uneven, nonrandom character of morbidity distributions. Approximately 15-20\% of children incur the majority of illness visits in primary care settings and sustain over $50 \%$ of the overall population morbidity $(1,2)$. This maldistribution of pediatric morbidity and

\footnotetext{
Received June 1, 1994; accepted June 29, 1995.

Correspondence: W. Thomas Boyce, M.D., Division of Behavioral and Developmental Pediatrics, University of California, 400 Parnassus Ave., Room A-203, San Francisco, CA 94143-0314.

Supported by National Institute of Child Health and Human Development Grant 1RO1 HD 24718 and the William T. Grant Foundation Grant 90-1306-89 to W.T.B., by National Institute of Child Health and Human Development Grant M01RR01271 to the Pediatric Clinical Research Center, and by National Institute of Mental Health Research Scientist Award MH00946 to M.R.G.

${ }^{1}$ Presented in part at the 1994 Annual Meeting of the Society for Pediatric Research, May 5, Seattle, WA.
}

$\Delta \mathrm{CD} 19^{+}$. These data suggest that: 1 ) school entry is a stressor capable of evoking elevations in cortisol and behavior problems, accompanied by shifts in functional and enumerative measures of immune status; and 2) children with greater adrenocortical reactivity have increases in B cell numbers and less effective B cell-mediated antibody production, whereas children with more behavioral difficulties show declines in all $\mathrm{T}$ and $\mathrm{B}$ cell subsets. (Pediatr Res 38: 1009-1017, 1995)

\section{Abbreviations}

$\Delta \mathrm{CD}^{+}, \Delta \mathrm{CD}^{+}, \mathrm{\Delta CD} 19^{+}$, change in $\mathrm{CD}^{+}, \mathrm{CD} 8^{+}, \mathrm{CD} 19^{+}$ cell subsets

$\Delta \mathbf{P W M}$, change in lymphoproliferative response to pokeweed mitogen

$\Delta$ cort, change in salivary cortisol

$\Delta O D$, change in OD

FACSCAN, fluorescence-activated cell sorter

HEPES, $N$-2-hydroxyethylpiperazine- $N$-2-ethanesulfonic acid

HPA, hypothalamic-pituitary-adrenocortical axis

PPS, pneumococcal polysaccharide care utilization persists even when school children are allowed to make independent care-seeking decisions (3). Further, there is evidence that patterns of disproportionately high morbidity continue beyond childhood in some individuals, and a subset of frequently ill pediatric patients become high utilizers of health care in adult patient groups (4-7).

Among the plausible explanations for unevenness in the distribution of pediatric morbidity is the possibility that some children sustain disproportionate rates of illness and injury as a consequence of greater exposure to psychologic stressors $(2$, 8). This explanation has been supported in recent years both by epidemiologic evidence for reliable stress-morbidity associations (9-11) and by psychobiologic evidence that pathophysiologic changes can accompany emotional stress (12-14). Investigators have documented relationships between stressors 
and a range of pediatric morbidities, including infections (15, 16), chronic health conditions $(17,18)$, minor and severe injuries $(19,20)$, and psychiatric or behavioral disorders $(21$, 22). Further, links have been demonstrated between stressful experience and a variety of biologic changes with pathogenic consequences, including neuroendocrine disturbances (23), changes in cardiovascular function $(24,25)$, and altered immune competence $(26,27)$.

New research examining the effects of psychologic stressors on immune function, for example, has substantially augmented the biologic plausibility of stress-infection associations noted in epidemiologic studies (28). In a program of study carried out primarily in adult subjects, investigators have documented effects of acute stressors, such as academic examinations or conjugal bereavement, on a variety of immune measures, which have included natural killer cell activity, the relative proportion of $\mathrm{CD}^{+}$(helper) and $\mathrm{CD}^{+}$(suppressor) $\mathrm{T}$ cells $\gamma$-interferon production, and lymphocyte proliferation in response to mitogen stimulation $(29-31)$. Other studies, in both adults $(31,32)$ and children $(33)$, have now linked stressinduced alterations in immune competence to rates of acute or recurrent infectious illnesses.

Despite consistent findings implicating stress in the pathogenic processes such as immunomodulation, the magnitude of stress-illness associations has remained disappointingly small, suggesting marked variability in children's behavioral or biologic responses to stressors. Individual differences in psychobiologic reactivity have been studied as means of assessing vulnerability to stressors and as a possible account for variability in rates of stress-related disease $(34,35)$. The prior work of Boyce et al. (12), Sallis et al. (36), Alpert and Wilson (37), and Matthews et al. (38) suggests the existence of marked differences in children's cardiovascular, neuroendocrine, or immunologic reactivity to stressors, and recent studies have linked exaggerated reactivity to increased illness or injury rates under conditions of naturally occurring stress $(33,39-42)$.

Among the difficulties in assessing psychobiologic reactivity in children is the invasiveness often inherent in measuring biologic parameters, and the lack of a standardized paradigm for evaluating effects of a normative childhood stressor. The current study was designed to address both difficulties by using behavioral reactivity and a noninvasive measure of adrenocortical reactivity-salivary cortisol-to predict changes in immune status after the normative stress of beginning school. Past studies have documented the validity of salivary cortisol determinations in young children $(43,44)$, and increases in salivary cortisol have been shown reliably to accompany diverse physical and emotional stressors (45-52). Further, the intensity of a noxious event has proved predictive of the magnitude of salivary cortisol responses (53), and glucocorticoids are known to affect leukocyte circulatory kinetics and cell functions $(54,55)$.

Although evidence is more limited, behavioral responses to stressors have also been associated with stress-related alterations in immune function $(56,57)$ and with immune-mediated disease processes (41). Positive associations have been demonstrated between behavioral and cortisol responses to stressors (51), but dissociations between behavioral and adrenocor- tical responses have also been found in human infants after acute stressors such as inoculation, heelsticks, or discharge exams $(48,51)$.

Finally, starting school is recognized as a universal childhood stressor, involving a range of cognitive, emotional, and interpersonal challenges $(58,59)$. Beginning school is also reliably accompanied by both an escalation in pathogen exposure and an acceleration in rates of clinical and subclinical infectious disease (60). For all of these reasons, we studied five year old children beginning kindergarten as a model for assessing biobehavioral changes that may accompany a normative stressor. We also examined whether behavioral and adrenocortical responses were associated with immunologic changes, which might plausibly attend the stress of beginning school. Specifically, we hypothesized that: 1) alterations in salivary cortisol and immune parameters would be found in pre- to postkindergarten entry measures and 2) children exhibiting greater cortisol and behavioral reactivity to the stressor would show greater immunologic changes.

\section{METHODS}

Subjects. A sample of 39 five-year-old children (mean age $=62 \mathrm{mo}$, range $=57-69 \mathrm{mo}$ ) was recruited as a subset of subjects in a larger study examining immunologic responses to the stress of starting kindergarten and subsequent respiratory illness incidence $(33,39)$. (Subjects for the current study represented the third cohort in the larger, 3-y, three-cohort project.) Children studied in the present project were those enrolled during the $3 \mathrm{rd} y$ of the larger study. The sample comprised 20 boys and 19 girls, with an ethnic distribution of 23 white, 8 African-American, 4 Asian, 3 Hispanic children, and 1 child of unknown ethnicity. Children taking medications and those with chronic medical conditions such as asthma, diabetes, sickle cell anemia, and juvenile rheumatoid arthritis were excluded from enrollment. Parents and children volunteering for the study were largely from educated, middle class families, with maternal education levels ranging from 10 to 22 $\mathrm{y}($ mean $=16 \mathrm{y})$. All study procedures were approved by the University of California Committee on Human Research, and informed consent was obtained from each family.

Design. Each mother-child pair made two laboratory visits over a 2-wk period: the first visit 1 wk before the start of kindergarten (time 1) and the second $1 \mathrm{wk}$ after school entry (time 2). At time 1, a venous blood sample was obtained, and children were immunized with $0.5 \mathrm{~mL}$ of 23 -valent pneumococcal vaccine (Pneumovax). Blood was transferred immediately to acid-citrate-dextrose, EDTA, and silicon tubes and transported at room temperature to our laboratory. Parents were instructed at time 1 in the home collection of approximately $1 \mathrm{~mL}$ of saliva on the day after the laboratory visit. Saliva was collected by the parent with a soft plastic pipette as the child sucked on a piece of hard candy; samples were frozen until delivery to the laboratory at time 2 . To preclude measuring exogenous cortisol present in milk or milk products (61), no saliva collections were carried out within 30 min after eating a meal or drinking milk. The day preceding the time 2 visit, the parent collected and froze a second saliva sample. 
This second sample was obtained at the same time of day (within $15 \mathrm{~min}$ ) as the collection time for sample 1, to avoid confounding related to normal circadian variation in cortisol secretion. The paired collection times ranged from 0600 to $0900 \mathrm{~h}$, and $60 \%$ of the samples were collected before $1000 \mathrm{~h}$. Both saliva samples were brought frozen to the time 2 laboratory visit. At time 2, a second venous blood sample was collected, and parents completed a brief questionnaire reporting on their child's behavioral adjustment to starting school. As was true for all children in the larger project, symptoms and signs of respiratory illnesses were ascertained for subjects in the present study from parent questionnaires administered every two weeks beginning at time 1 for a 12-wk period. Except as they pertain to cortisol and immune measures in period surrounding school entry, the respiratory illness measures are not discussed further here, but will be the subject of subsequent reports.

Behavioral difficulty. Parents completed a questionnaire 1 wk after kindergarten entry addressing three aspects of their child's behavioral adjustment to school. First, a 20-item checklist was used to report on the appearance of reactive behavior problems that the parent deemed related to starting school. These included a variety of both internalizing and externalizing behavioral symptoms, such as excessive crying, separation difficulties, sleep disturbances, unusual aggression, temper tantrums, or school refusal. Second, parents completed a 5-point scale describing the level of difficulty experienced by the child due to school-related changes in daily routines. Third, a 5-point scale was used to estimate the degree of difficulty in the child's overall adjustment to starting kindergarten. Scores on each of the three scales were standardized and summed, creating an aggregate index of behavioral difficulty with school adjustment.

Cortisol. Saliva samples were stored at $-20^{\circ} \mathrm{C}$ until analyzed. All samples were assayed in a single batch to avoid error from interassay variation. One person assayed all samples in duplicate to quality control standards using a modification of the Amersham International Amerlex cortisol RIA kit procedures. This assay is highly sensitive and specific to cortisol, with inter- and intraassay coefficients of variation averaging 7 and $4 \%$, respectively. Cortisol reactivity to the stress of beginning school was measured as the change $(\Delta)$ score computed by subtracting the time 1 cortisol from the time 2 value. Positive scores thus reflected an increase in cortisol levels after school entry, whereas negative scores reflected a decline.

Immune assays. Immune reactivity to the stress of starting school was also measured as a $\Delta$ score, computed by subtracting the immune measure at time 1 from that at time 2 . As with cortisol reactivity, positive scores reflected an increase or up-regulatory change in the immune parameter, whereas negative scores denoted a decline or down-regulatory change. Immune measures were selected to be broadly representative of the child's immune status, and assays thus included enumerative and functional measures of both cellular and antibodymediated components of immune competence. Enumerative assays were: quantitative counts of $\mathrm{T}$ cell subsets for $\mathrm{CD} 4^{+}$ (helper/inducer) and $\mathrm{CD}^{+}$(suppressor/cytotoxic) cells and of the number of $\mathrm{CD} 19^{+}$(B lymphocyte) cells. Functional mea- sures were lymphocyte proliferative responses to PWM and the number of positive serum antibody responses to PPS vaccine.

For the purposes of cellular studies, the mononuclear cell fraction was isolated by centrifugation on a Ficoll-Hypaque density gradient. Responses to PWM were determined by culturing peripheral blood mononuclear cells at $5 \times 10^{5} / \mathrm{mL}$ in RPMI supplemented with 15\% FCS, $25 \mathrm{mM}$ HEPES, $2 \mathrm{mM}$ glutamine, $100 \mu \mathrm{g}$ of streptomycin, and $100 \mathrm{U}$ of penicillin/ $\mathrm{mL}$. Two hundred microliters of peripheral blood mononuclear cells were added to round bottomed microtiter plates and incubated with PWM (Life Technologies, Inc.) at 5 and 10 $\mu \mathrm{L} / \mathrm{mL}$ in $5 \% \mathrm{CO}_{2}$. After a 4 -d incubation period, cultures were labeled with tritiated thymidine and harvested onto glass fiber filters. Enumeration of $\mathrm{CD} 4^{+}, \mathrm{CD} 8^{+}$, and $\mathrm{CD} 19^{+}$cells was performed on 5,000 cells in $100 \mu \mathrm{L}$ of whole blood, using the FACSCAN and MAb from the Coulter Laboratories. Actual numbers of $\mathrm{T}$ cell phenotypes were then derived by multiplying the percentages of $\mathrm{CD} 4^{+}, \mathrm{CD} 8^{+}$, and $\mathrm{CD} 19^{+}$cells by the absolute lymphocyte count.

Antibody response to PPS was measured in our laboratory by a modification of the method published by Koskela (62). Briefly, ELISA plates were coated with PPS antigen (types 3, 4 , or 19 ) at $10 \mu \mathrm{g} / \mathrm{mL}$ in carbonate buffer, $\mathrm{pH}$ 9.6. After overnight incubation at $4^{\circ} \mathrm{C}$, the plates were washed in PBS/ Tween, blocked with $0.25 \%$ BSA plus $\mathrm{NaN}_{3}$, washed, and incubated for $1 \mathrm{~h}$ at $37^{\circ} \mathrm{C}$ with a 1:200 dilution of pre- and postimmunization serum samples. The plates were then washed and incubated $\left(1 \mathrm{~h}\right.$ at $\left.37^{\circ} \mathrm{C}\right)$ with a $1: 1000$ dilution of horseradish peroxidase-conjugated goat anti-human IgG, IgA, or IgM. The substrate used was $o$-phenylenediamine dihydrochloride. OD was measured at $492 \mathrm{mn}$ on the Bio-Rad ELISA reader, and the results were expressed as $\triangle O D$ between preand postimmunization samples. Any increase in OD greater than 0.250 was considered a positive response, and antibody response scores were expressed as the number of positive responses out of six antibody assays (IgG, IgA, and $\operatorname{IgM}$ antibody to PPS3 and PPS4). This approach to scoring was based on prior evidence that primary antibody responses to pneumococcal antigens can occur in any of the three immunoglobulin subclasses and that responsivity can be most accurately assessed using isotype responses to more than one polysaccharide antigen. PPS 3 and PPS4 were selected because of type 3's strong antigenicity and type 4's weaker antigenicity, which together provide a broad assay of type-specific antibody responses to vaccine.

Statistical analysis. After examination of frequency distributions for independent and outcome variables, $t$ tests were conducted to compare time 1 and time 2 means. Two-tailed Pearson correlation coefficients were then calculated as measures of 1 ) associations among independent variables and 2) the bivariate relations representing the principal study hypotheses. To take into account diurnal variation in salivary cortisol measures, partial correlations controlling for collection time were used to confirm all reported associations involving cortisol measures. Finally, multiple linear regression models were used to examine possible interactions between behavioral difficulty and cortisol reactivity in predicting immune responses after school entry. 


\section{RESULTS}

Table 1 displays the distribution characteristics for independent and outcome variables, along with the corresponding $\Delta$ scores and results of $t$ tests for differences between time 1 and time 2 values. Time 2 scores for behavioral difficulty in adjusting to school reflected moderate distress. An average of three new, reactive behavior problems were reported by parents, and difficulties due to school-related changes in routine were given a mean score of 3.4 on the 1-5 scale. Overall, difficulty in adjustment was rated by parents at a mean of approximately 2 on a $1-5$ scale. Only $8 \%$ of parents reported no new school entry-related behavior problems or recorded a 1 ("none") in rating children's distress due to changes in routine.

Salivary cortisol levels significantly increased from a time 1 mean of $0.39 \mu \mathrm{g} / \mathrm{dL}$ to a time 2 mean of $0.49 \mu \mathrm{g} / \mathrm{dL}$, consistent with a moderate activation of the HPA in response to the stress of kindergarten entry. As shown in Figure $1, A$ and $B$, more striking than the group increase in mean salivary cortisol level was the extensive individual variability in cortisol values at times 1 and 2. Children followed a broad range of individual trajectories, some showing sharp increases in cortisol levels, whereas others showed no increase or even a decline.

Although considerable variation was also found for measures of immune status at both time points, all values remained

Table 1. Distributions of independent and outcome variables $(n=39)$ and $t$ tests for changes, time 1 to time 2

\begin{tabular}{|c|c|c|}
\hline Variables & Mean $\pm S D$ & Range \\
\hline \multicolumn{3}{|l|}{ Behavioral difficulty (time 2) } \\
\hline Reactive behavior problems & $2.9 \pm 2.6$ & $0-11$ \\
\hline Change in daily routines & $3.4 \pm 1.4$ & $1-5$ \\
\hline Difficulty in adjustment & $1.7 \pm 0.8$ & $1-3$ \\
\hline Combined score & $-0.1 \pm 2.1$ & $-3.9-6.0$ \\
\hline \multicolumn{3}{|l|}{ Cortisol response $(\mu \mathrm{g} / \mathrm{dL})$} \\
\hline Salivary cortisol, time 1 & $0.39 \pm 0.28$ & $0.05-1.05$ \\
\hline Salivary cortisol, time 2 & $0.49 \pm 0.36$ & $0.05-1.30$ \\
\hline$\Delta$ Cortisol & $0.10 \pm 0.28 *$ & $-0.72-0.85$ \\
\hline \multicolumn{3}{|l|}{ Immune responses } \\
\hline $\mathrm{CD}^{+}$, time $1\left(\operatorname{cell} / \mathrm{mm}^{3} \times 10^{3}\right)$ & $1.19 \pm 0.39$ & $0.61-2.44$ \\
\hline $\mathrm{CD}_{4}^{+}$, time 2 & $1.30 \pm 0.49$ & $0.53-2.69$ \\
\hline$\Delta \mathrm{CD}^{+}$ & $0.14 \pm 0.31^{* *}$ & $-0.85-0.80$ \\
\hline $\mathrm{CD}^{+}$, time $1\left(\mathrm{cell} / \mathrm{mm}^{3} \times 10^{3}\right)$ & $0.91 \pm 0.34$ & $0.45-1.71$ \\
\hline $\mathrm{CD} 8^{+}$, time 2 & $0.99 \pm 0.39$ & $0.38-2.30$ \\
\hline$\Delta \mathrm{CD}^{+}$ & $0.07 \pm 0.27$ & $-0.68-0.64$ \\
\hline $\mathrm{CD} 19^{+}$, time $1\left(\mathrm{cell} / \mathrm{mm}^{3} \times 10^{3}\right)$ & $0.65 \pm 0.27$ & $0.13-1.24$ \\
\hline $\mathrm{CD} 19^{+}$, time 2 & $0.71 \pm 0.29$ & $0.14-1.35$ \\
\hline$\Delta \mathrm{CD} 19^{+}$ & $0.05 \pm 0.19 \dagger$ & $-0.32-0.54$ \\
\hline $\begin{array}{l}\text { PWM response, time } 1 \\
\left(\text { counts } / \min \times 10^{4}\right)\end{array}$ & $3.17 \pm 1.52$ & $1.06-5.95$ \\
\hline PWM response, time 2 & $2.16 \pm 0.96$ & $0.87-4.72$ \\
\hline$\triangle \mathrm{PWM}$ & $-1.14 \pm 1.53^{* * *}$ & $-4.72-1.31$ \\
\hline $\begin{array}{l}\text { Antibody responses to } \\
\text { pneumococcal antigens }\end{array}$ & $3.2 \pm 1.9$ & $0-6$ \\
\hline
\end{tabular}

Sum of standardized scores for reactive behavior problems, change in daily routines, and difficulty in adjustment.

$\dagger p \leq 0.10$.

$* p \leq 0.05$.

$* * p \leq 0.01$.

$* * * p \leq 0.001$ for -tests for differences between time 1 and 2 means. (Note: no $t$ test was completed on the behavioral difficulty and antibody response scores, because these variables were assessed only at time 2 .)
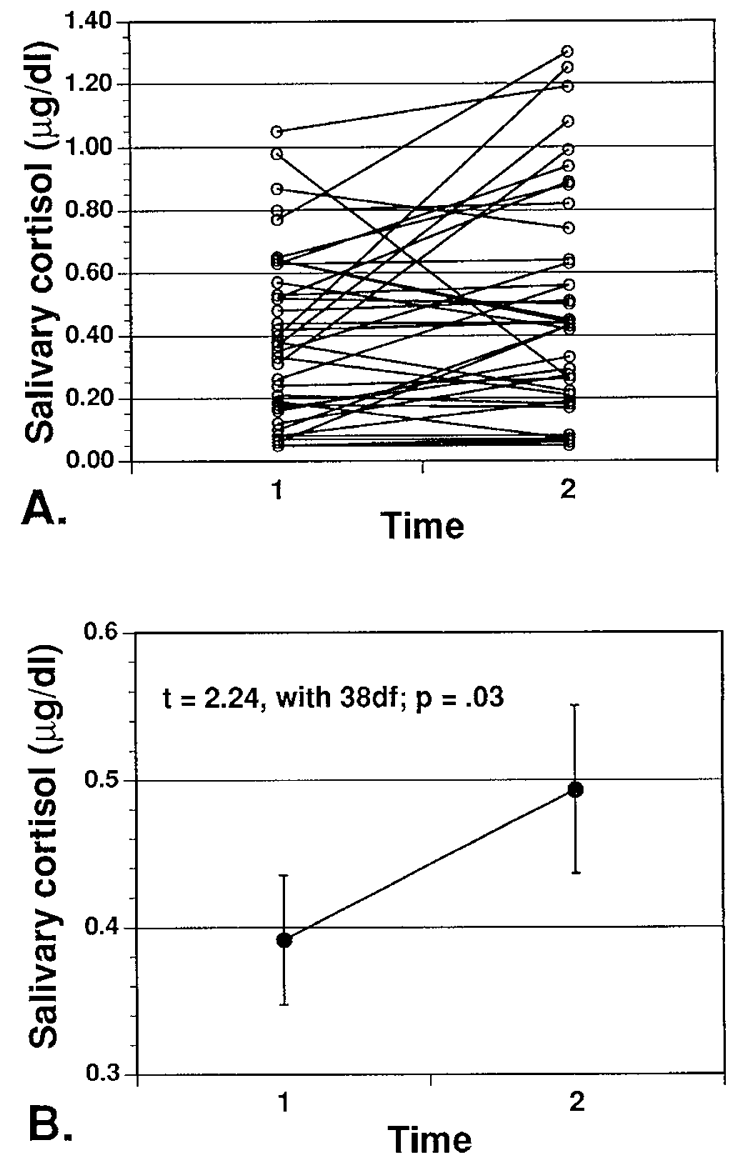

Figure 1. (A) Change in salivary cortisol, pre- to postkindergarten entry among individual children $(n=39) ; B$, change in mean salivary cortisol, preto postkindergarten entry.

within the limits of normal for children of this age. (All immune measures were between the 5th and 95th percentiles for values from our laboratory in the sample of 100 healthy children assessed each year.) A significant increase was identified after school entry for $\mathrm{CD}^{+}{ }^{+}$cells, and there was a trend toward an increase in $\mathrm{CD} 19^{+} \mathrm{B}$ cells. $\triangle \mathrm{PWM}$, on the other hand, showed a significant decrease after school entry. Out of six type-specific pneumococcal antibody assays, children showed a positive response in an average of 3 , with a range of $0-6$ positive assays.

Table 2 displays bivariate relations among independent and outcome variables, as well as partial correlations between independent and outcome measures controlling for maternal education. Table $2 \mathrm{~A}$ shows that time 1 and time 2 salivary cortisols were highly correlated and that the time 2 level was strongly related to $\Delta$ cort scores. These findings confirm that higher cortisol change scores were produced primarily by increases in cortisol levels in the postkindergarten period. Also of note is the finding that $\Delta$ cort was unrelated to behavioral difficulties during adjustment.

Table 2B presents significant, positive associations between maternal education and both $\Delta$ cort and $\Delta \mathrm{CD} 8^{+}$. In addition, a borderline significant relation was found between education and $\Delta \mathrm{CD} 4^{+}$. These unanticipated associations suggest that the children of more highly educated mothers sustained more 
Table 2. Bivariate relations among independent and outcome variables (Pearson correlation coefficients, $n=39$ )

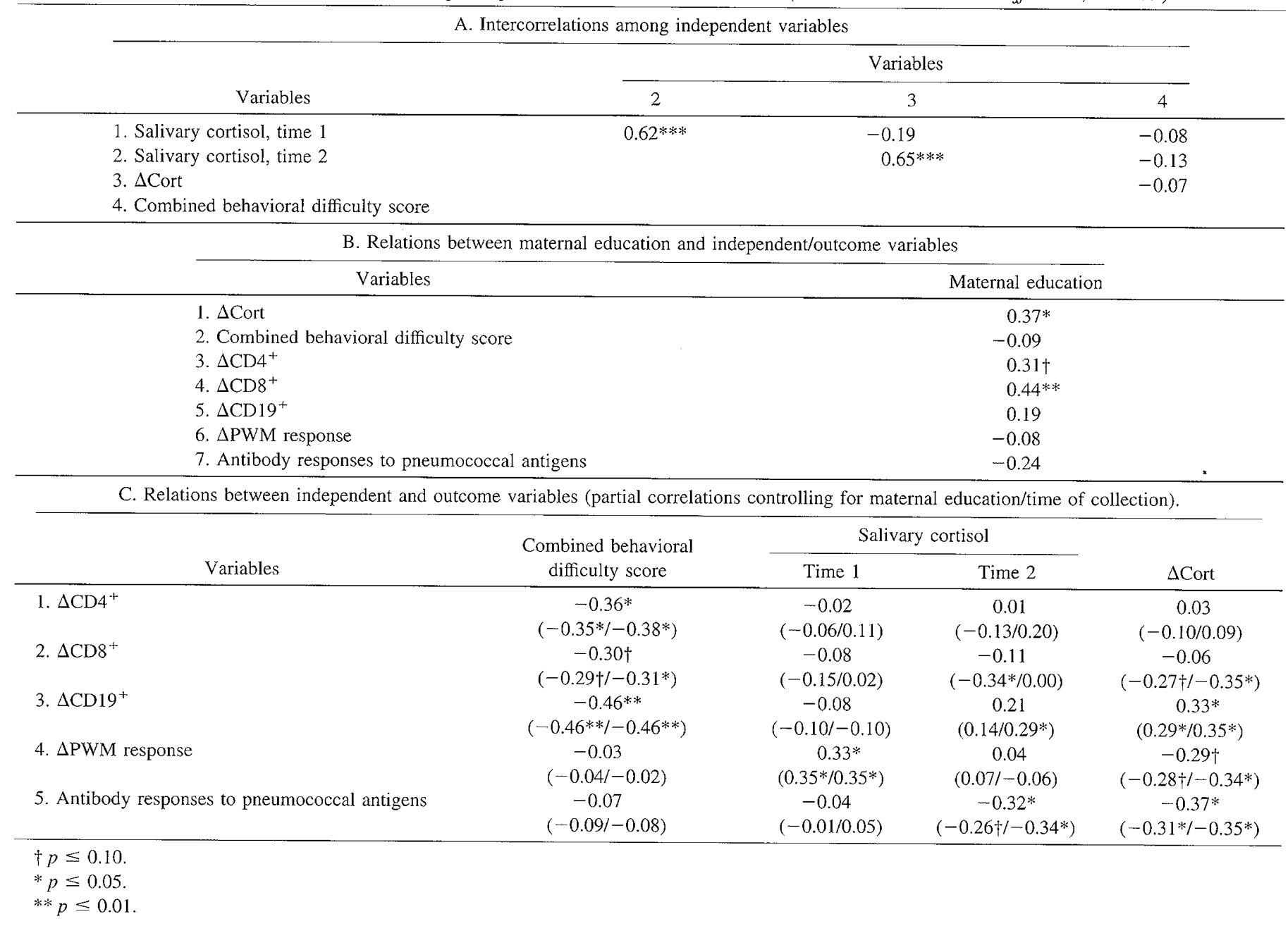

adrenocortical activation at school entry and showed greater up-regulatory changes in $\mathrm{T}$ cell subsets.

Table $2 \mathrm{C}$ reveals that behavioral adjustment difficulties and adrenocortical activation were significant correlates of the immunologic changes that followed kindergarten entry. The table also indicates that these associations were largely unaffected by adjustment for either the level of maternal education or the time of sample collection. Not surprisingly, collection time had no discernible effects on the correlations between behavioral difficulty and immune change scores. Few substantive alterations in the pattern of results were identified even for $\Delta$ cort after controlling for time of collection. A significant, inverse association between $\Delta$ cort and changes in $\mathrm{CD}^{+}$cells became apparent, however, suggesting that after adjustment for time of saliva collection higher cortisol reactivity was associated with a decline in $\mathrm{CD}^{+}$cells.

Figure 2 provides scatter plots of the six significant or borderline significant associations consistently identified in bivariate or partial correlations. Parental ratings of behavioral difficulties with school adjustment were related to several alterations in immune parameters. As shown in Figure 2, children with behaviors signaling greater adjustment difficulties showed declines in $\mathrm{CD} 19^{+}, \mathrm{CD} 4^{+}$, and to some extent $\mathrm{CD}^{+}$cells, whereas children with less behavioral difficulty tended to show $\mathrm{B}$ and $\mathrm{T}$ cell increases. Thus, more severe behavioral adjustment problems as perceived by children's parents predicted down-regulatory responses in cell numbers.

Changes in salivary cortisol, on the other hand, showed a different profile of associations with immune parameters. Cortisol changes scores were positively associated with $\Delta \mathrm{CD} 19^{+}$ and inversely associated with pneumococcal antibody production. Children showing increases in salivary cortisol levels postschool entry had increases in B cell numbers, but produced fewer type-specific antibodies to pneumococcal antigens. There was also a trend toward positive cortisol $\Delta$ scores predicting declines in lymphoproliferative responses to PWM. As indicated by the correlations displayed in Table $2 \mathrm{C}$, this borderline, inverse association between $\Delta$ cort and $\triangle \mathrm{PWM}$ was attributable primarily to a positive relation between baseline (time 1) salivary cortisol levels and increases in PWM response.

Changes in salivary cortisol and immune functions, as well as the development of behavior difficulties, might plausibly be related to infectious illnesses appearing during the first $2 \mathrm{wk}$ of school. Such relations, if present, could have confounded the associations reported above between cortisol, behavior problems, and immune measures, because 15 of the 39 children developed respiratory illnesses in the first $2 \mathrm{wk}$ of school. No 

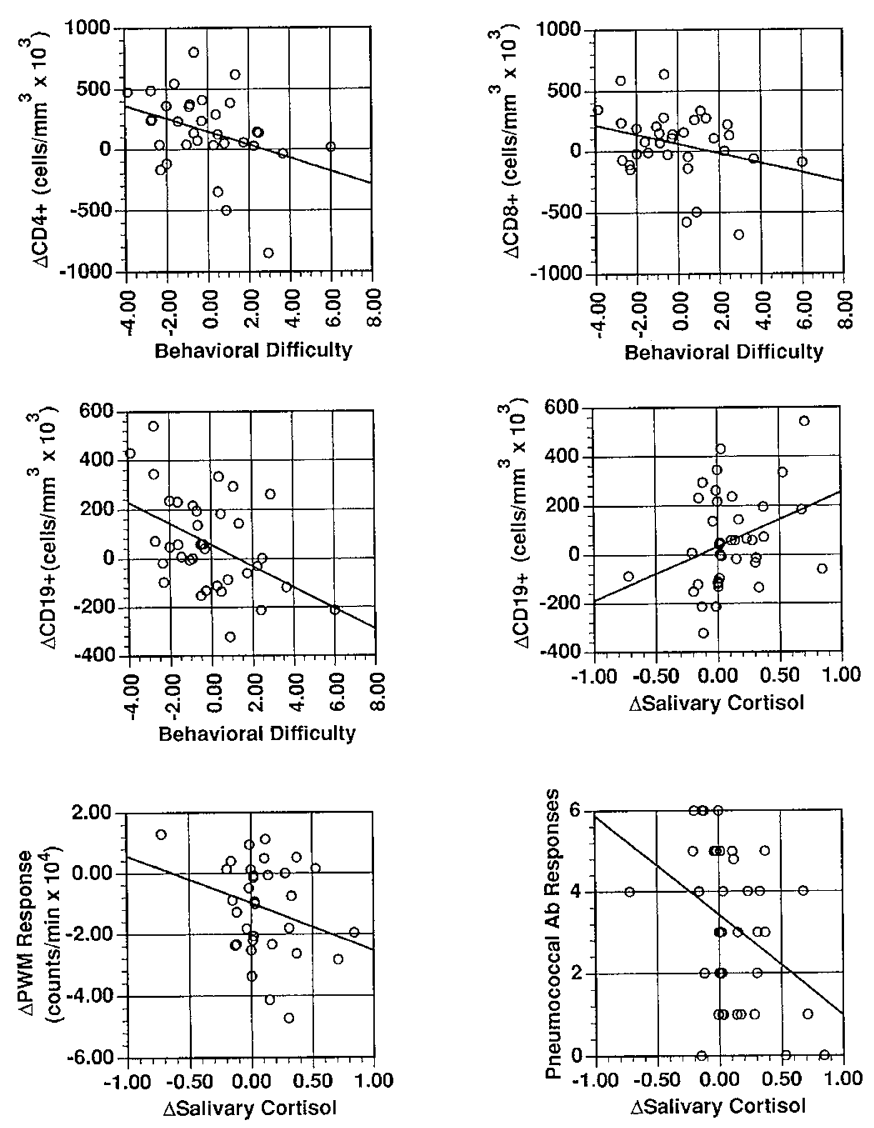

Figure 2. Scatter plots of significant or borderline significant associations between independent and outcome variables $(n=39)$.

statistically significant associations were found, however, between the number of respiratory illness symptoms reported by parents in the 2-wk period and either the independent or outcome measures (Pearson $r$ values $=-0.06$ to $0.28, p=$ NS). Associations between adrenocortical, behavioral, and immunologic responses to school entry were thus unconfounded by the development of intercurrent illnesses.

Finally, because behavioral and adrenocortical responses were uncorrelated, but were both related to changes in immune parameters, multiple linear regression was used to assess their independent and interactive effects on immune end points. Behavioral difficulty and cortisol change scores were entered in step 1 , followed in step 2 by the first order interaction term for behavior problems $\times$ cortisol response. Five regression equations were computed, corresponding to the five immune change scores. These analyses confirmed the independent main effects of behavioral difficulty and $\Delta$ cort, reported in Table $2 \mathrm{C}$, but revealed no signficant interactions. A final set of regression analyses, which added the main effect of maternal education, also made no substantive changes in the conclusions drawn from bivariate associations.

\section{DISCUSSION}

Data from this study suggest several conclusions of relevance to research on the psychobiology of stress in children. First, our results indicate that the mild, normative stressor of beginning school is associated with moderate increases in salivary cortisol, commensurate with those previously observed in young children undergoing low level psychologic stress $(46,49,52)$. Because the stressors that accompany kindergarten entry presumably continue for weeks beyond the first day of school, we were unable to control for experimental order effects by shifting the schedule of time 1 and time 2 blood samples. (Further, examination of an additional, control group of children undergoing a more benign life transition was precluded by human subjects considerations surrounding the use of serial venipunctures.) Nonetheless, school entry appears to represent a useful and accessible model for studying stress effects in normal children. Most parents in this study also reported moderate and problematic alterations in their children's behavior, reflecting active, adaptive efforts to accommodate to new school settings. It has been previously noted that individual differences in behavior problems are accentuated during periods of stressful transition, such as starting school (63).

Second, measures of immunologic function were found to shift significantly over the 2-wk period surrounding the start of school. Overall, such shifts reflected modest increases in cell numbers and diminutions in functional parameters, although none of the changes resulted in immune measures outside the range of normal for children of this age. Change scores for $\mathrm{CD}^{+}$and $\mathrm{CD} 19^{+}$cells showed, at the group level, increases in cell numbers, whereas lymphoproliferative responses to PWM declined. These results correspond to those of previous studies finding elevations in immune cell numbers (64-67) and decrements in cell function $(64,66,68,69)$ after acute psychologic stress.

Third, maternal education was a significant or borderline significant correlate of change scores for salivary cortisol, $\mathrm{CD} 4^{+}$cells, and $\mathrm{CD} 8^{+}$cells. Children of more highly educated mothers, in this largely upper middle class sample, showed greater adrenocortical activation and larger increases in $\mathrm{T}$ cell subsets than did their peers whose mothers were less educated.

Finally, behavioral and adrenocortical responses to kindergarten entry were associated with alterations in both enumerative and functional measures of immune status. Specifically, parent-reported behavioral difficulties were predictive of declines in $\mathrm{CD} 19^{+}$, B lymphocytes, and in both $\mathrm{CD}^{+}$(helper) and $\mathrm{CD}^{+}$(suppressor) $\mathrm{T}$ cells. Increases in salivary cortisol after school entry were predictive, on the other hand, of elevations in B lymphocytes, fewer antibody responses to pneumococcal vaccine, and diminished lymphoproliferative responses over the same 2-wk period. None of these relations were confounded by intercurrent infectious illnesses, which have been known to alter both immune parameters and cortisol responsivity (70), and the pattern of associations was not substantively altered by adjustment for either maternal education or the time of day at which the sample collection was completed.

Activation of the HPA axis has been regarded in past research as a defining psychobiologic parameter of the human stress response $(71,72)$. Corticotropin-releasing factor induction of pro-opiomelanocortin gene expression results in ACTH and cortisol secretion, which in turn effects profound changes in a variety of target organs (72-74). Immunologic influences 
of glucocorticoids include effects on leukocyte circulatory kinetics, leukocyte functions, and the permeability of the vascular bed (55). Cortisol reduces the number of circulating lymphocytes, monocytes, and macrophages, and increases circulating neutrophils through redistributions into or out of lymphoid tissues $(55,75,76)$. Within lymphocytic cell lines, cortisol appears to alter function by depressing proliferative responses to mitogens and antigens (55) and by decreasing production of cytokines and prostaglandins $(71,77)$. Glucocorticoids also have direct effects on vascular tone and were shown by Ebert and Barclay (78) to decrease leukocyte migration into inflammatory sites by augmenting the integrity of the microvascular endothelium.

Most recently, and perhaps of greatest importance to the findings of this study, glucocorticoids have been shown to have complex, bidirectional influences on the deployment of the components of the immune system through transcriptional regulation of IL-2 and IL-4 production $(79,80)$. It has been shown, for example, that the effects of cortisol on mitogen responses are highly dependent on cortisol concentration (81). Incubation of lymphocytes in glucocorticoids at low concentrations results in enhancement of lymphoproliferative responses, whereas high concentrations are associated with immune inhibition. The molecular, epigenetic basis for these bidirectional effects appears to be corticoid-dependent modulation of $\mathrm{CD}^{+}$cell subtypes and their relative productions of IL-2 and IL-4. Under conditions of stress, glucocorticoids appear to cause a switch away from $\mathrm{T}_{\mathrm{H}} \mathrm{l}$ cell synthesis of IL-2, the principal cytokine stimulator of cellular immune responses, toward a predominance of $\mathrm{T}_{\mathrm{H}} 2$ cell elaboration of IL-4, the cytokine driving $\mathrm{B}$ cell antibody production (79). The result is a dramatic shift in the balance of immune processes, away from cell-mediated responses toward a predominantly humoral response.

One account for the associations between behavioral difficulties, cortisol reactivity, and immune responses observed in this study is thus the complex, bidirectional regulatory effects of glucocorticoids on $\mathrm{T}$ cell subtypes and their associated cytokines. Although we were unable to measure $\mathrm{CD}^{+}$cell subtypes and cytokine production in this study, the pattern of enumerative cellular changes associated with adrenocortical activation (i.e. increases in $\mathrm{CD} 19^{+} \mathrm{B}$ cells) suggests a stressorrelated shift toward antibody-mediated immune responses. The decline in mitogen responses, also associated with adrenocortical activation in this study, may reflect the effects of higher blood levels of cortisol on lymphoproliferative processes. The decline in antibody production among cortisol-reactive subjects may be related to measurement either too early or too late in the mobilization of the $B$ cell line to record the expected boost in antibody production.

The profile of immune changes seen in children with visible behavioral difficulties after school entry may reflect, in contrast, a different set of immunomodulatory influences. In these children, significant declines were noted in both $\mathrm{T}\left(\mathrm{CD}^{+}\right.$and $\left.\mathrm{CD} 8^{+}\right)$and $\mathrm{B}\left(\mathrm{CD} 19^{+}\right)$cell lines, suggesting a more general down-regulatory effect. It is possible that other, unmeasured neuroendocrine mediators, such as catecholamines (82) or endogenous opiates (83), could have played a role in the immune changes identified in subjects displaying more severe behavioral responses.

Finally, the association of maternal education with both adrenocortical and immune reactivity was an unanticipated finding. It is tempting to interpret the finding as a manifestation of the higher expectations for school and academic success that are known to characterize the families of more highly educated parents. To the degree that maternal education is a reflection of social status, such a formulation is also consistent with past observations on the relation of social dominance to adrenocortical responses in nonhuman primates. Higher cortisol levels have been consistently found, for example, among the more dominant animals in groups of wild baboons during periods of social instability and change (84).

Previous findings in our laboratory are also quite consistent with the immune effects noted in the cortisol-responsive children in this study. In a study involving 99 kindergarten-aged children, Boyce et al. (39) found that children from highly stressed families sustained significantly higher rates of respiratory illnesses in the weeks after school entry. Higher illness incidences were found, however, only among the subset of children showing postkindergarten increases in B cell numbers. In another study (33), children with up-regulatory changes in helper:suppressor cell ratios after school entry showed accelerations in respiratory illness rates in the 6-wk aftermath of a major earthquake. Taken together, these findings, along with those from the current study, suggest that the cortisolassociated changes in immune function-comprising increases in cell numbers and diminutions in cell functions-may be those reflecting a maladaptive response and altering clinical susceptibility to infection during psychologic stress.

Stress-related cortisol secretion shows striking individual differences in response magnitude $(50,85)$. In animal models, early stress (e.g. handling in the neonatal period) appears to decrease glucocorticoid responses to stressors in later life (86). Circadian rhythms in cortisol secretion appear by about 3 mo of age in human infants $(52,87)$, and a decline in cortisol response to stress over the first months of life has been noted (50). In a series of studies by Gunnar $(46,47,49)$ and Lewis $(51,52)$ and their colleagues, cortisol responses have been studied in relation to a diversity of environmental events and perturbations, including maternal-infant separations, car rides, swimming lessons, and routine immunizations. Individual differences in cortisol response in such settings have been shown to be reliable $(52,53)$, related to aspects of emotional temperament (49), and modifiable by altering aspects of the social environment $(47,88)$. Possibly related to variations in cortisol responsivity, individual differences in immune reactivity to stressors have also been demonstrated in both human subjects (66) and nonhuman primates (89).

Individual differences in cortisol reactivity have been studied only infrequently in relation to behavioral responses to stressors. In contrast to the findings of the present work, studies by Lewis and colleagues $(50,51)$ have found moderate but significant correlations in infancy between cortisol and behavioral responses (i.e. crying) to the nociceptive stimulus of inoculation. On the other hand, Gunnar et al. (48) found habituation of HPA reactivity, but not of distress behaviors, to 
the perturbation of newborn physical examinations, a finding suggesting a dissociation between adrenocortical and behavioral response modalities. Similarly, Lewis et al. (51) found that, in children showing a dissociated pattern of cortisol and behavioral responses to inoculation, more Caucasian American infants were among those with high behavioral and low cortisol responses, whereas more Japanese infants exhibited the opposite pattern. These studies together suggest that both behavioral and adrenocortical systems are reactive in some degree to nociceptive stimuli, but that responses to nonpainful, psychologic, or emotional stressors may be dissociated. Findings from past research suggest that the relative magnitudes of behavioral and adrenocortical responses are dependent upon aspects of temperament and the sociocultural environment, psychosocial factors which together influence the efficacy of a child's coping and adaptive capacity. Findings from the present research, on the other hand, suggest that behavioral and adrenocortical reactivity may be associated with different profiles of immunologic effects, which may in turn have different or even opposing influences on susceptibility to immune-mediated disease.

Individual differences in profiles of stressor effects might have important influences on disease end points ranging from infection and allergy to malignancy and autoimmune disorders. Continued investigation of individual differences in stress response could conceivably lead to a richer understanding of children's unique vulnerabilities and the highly uneven distribution of disease events in childhood populations.

\section{REFERENCES}

1. Starfield B, Van Den Berg BJ, Steinwachs DM, Katz HP, Horn SD 1979 Variations in utilization of health services by children. Pediatrics 63:633-641

2. Starfield B, Hankin J, Steinwachs D, Horn S, Benson P, Katz H, Gabriel A 1985 Utilization and morbidity: random or tandem? Pediatrics 75:241-247

3. Lewis CE, Lewis MA, Lorimer A, Palmer BB 1977 Child-initiated care: The use of school nursing services by children in an "adult-free" system. Pediatrics 60:499-507

4. Densen PM, Shapiro S, Einhorn M 1959 Concerning high and low utilizers of service in a medical care plan, and the persistence of utilization levels over a three year period. Milbank Mem Fund Q 37:217-250

5. Mechanic D 1964 The influence of mothers on their children's health attitudes and behavior. Pediatrics 444:453

6. Mechanic D 1979 The stability of health and illness behavior: Results from a 16-year follow-up. Am J Public Health 69:1142-1145

7. Newacheck PW, Halfon N 1986 The association between mother's and children's use of physician services. Med Care 24:30-38

8. Green M 1986 Vulnerable child syndrome and its variants. Pediatr Rev 8:75-80

9. Brown GW, Harris TO 1989 Life Events and Illness. Guilford Press, New York

10. Dohrenwend BS, Dohrenwend BP 1981 Stressful Life Events and Their Contexts. Rutgers University Press, New Brunswick, NJ

11. Haggerty RJ 1980 Life stress, illness and social supports. Dev Med Child Neurol 22:391-400

12. Boyce WT, Barr RG, Zeltzer LK 1992 Temperament and the psychobiology of childhood stress. Pediatrics 90:483-486

13. Chrousos GP, Gold PW 1992 The concepts of stress and stress system disorders: overview of physical and behavioral homeostasis. JAMA 267:1244-1252

14. Gunnar MR 1987 Psychobiological studies of stress and coping: an introduction. Child Dev 58:1403-1407

15. Boyce WT, Jensen EW, Cassel JC, Collier AM, Smith AH, Ramey CT 1977 Influence of life events and family routines on childhood respiratory tract illness. Pediatrics 60:609-615

16. Meyer RJ, Haggerty RJ 1962 Streptococcal infections in families: Factors altering individual susceptibility. Pediatrics 29:539-549

17. Stein SP, Charles ES 1975 Emotional factors in juvenile diabetes mellitus: experience of eight diabetic children. Psychosom Med 37:237-244

18. Strunk RC, Mrazek DA, Fukuhara JT, Masterson J, Ludwick SK, LaBrecque JF 1989 Cardiovascular fitness in children with asthma correlates with psychologic functioning of the child. Pediatrics 84:460-464

19. Boyce WT, Sobolewski S, Schaefer C 1989 Recurrent injuries in school-age children. Am J Dis Child 143:338-342

20. Horwitz SM, Morgenstern H, DiPietro L, Morrison CL 1988 Determinants of pediatric injuries. Am J Dis Child 142:605-611
21. Rutter M 1989 Pathways from childhood to adult life. J Child Psychol Psychiatr 30:23-51

22. Werner EE, Smith RS 1983 Vulnerable but Invincible: A Study of Resilient Children. McGraw-Hill, New York

23. Dahl RE, Ryan ND, Puig-Antich J, Nguyen NA, Al-Shabbout M, Meyer VA, Perel J 1991 24-Hour cortisol measures in adolescents with major depression. Biol Psychiatry $30: 25-36$

24. Falkner B, Ragonesi S 1986 Psychosocial stress and reactivity as risk factors of cardiovascular disease. J Am Acad Child Psychiatry 25:779-784

25. Turner JR 1992 Individual Differences in Cardiovascular Responses to Stress. Plenum, New York

26. Ader R, Felten DL, Cohen N 1991 Psychoneuroimmunology. Academic Press, New York

27. Herbert TB, Cohen S 1993 Depression and immunity: a meta-analytic review. Psychol Bull 113:472-486

28. Cohen S, Williamson GM 1991 Stress and infectious disease in humans. Psychol Bull 109:5-24

29. Kiecolt-Glaser JK, Glaser R, Strain EC, Stout JC, Tarr KL, Holliday JE, Speicher CE 1986 Modulation of cellular immunity in medical students. J Behav Med 9:311-20

30. Kiecolt-Glaser JK, Glaser R 1987 Psychosocial moderators of immune function. Annu Behav Med 9:16-20

31. Glaser R, Rice J, Sheridan J, Fertel R, Stout J, Speicher C, Pinsky D, Kotur M, Post A, Beck M, Kiecolt-Glaser J 1987 Stress-related immune suppression: health implications. Brain Behav Immun 1:7-20

32. Kemeny ME, Cohen F, Zegans LA, Conant MA 1989 Psychological and immunological predictors of genital herpes recurrence. Psychosom Med 51:195-208

33. Boyce WT, Chesterman EA, Martin N, Folkman S, Cohen F, Wara D 1993 Immunologic changes occurring at kindergarten entry predict respiratory illnesses following the Loma Prieta earthquake. J Dev Behav Pediatr 14:296-303

34. Boyce WT, Jemerin JJ 1990 Psychobiological differences in childhood stress response: I. Patterns of illness and susceptibility. J Dev Behav Pediatr 11:86-94

35. Jemerin JJ, Boyce WT 1990 Psychobiological differences in childhood stress response. II Cardiovascular markers of vulnerability. J Dev Behav Pediatr 11:140-150

36. Sallis JF, Dimsdale JE, Caine C 1988 Blood pressure reactivity in children. $\mathfrak{J}$ Psychosom Res 32:1-12

37. Alpert BS, Wilson DK 1992 Stress reactivity in childhood and adolescence. In Turner JR (ed) Individual Differences in Cardiovascular Responses to Stress. Plenum, New York

38. Matthews KA, Woodall KL, Stoney CM 1990 Changes in and stability of cardiovascular responses to behavioral stress: results from a four-year longitudinal study of children. Child Dev 61:1134-1144

39. Boyce WT, Chesney M, Alkon-Leonard A, Tschann $\}$, Adams S, Chesterman B, Cohen F, Kaiser P, Folkman S, Wara D 1995 Psychobiologic reactivity to stress and childhood respiratory illnesses: results of two prospective studies. Psychosom Med (in press)

40. Liang SW, Boyce WT 1993 The psychobiology of childhood stress. Curr Opin Pediatr 5:545-551

41. Lewis M, Thomas DA, Worobey J 1990 Developmental organization, stress, and illness. Psychol Sci 1:316-318

42. Bell IR, Jasnoski ML, Kagan J, King DS 1990 Is allergic rhinitis more frequent in young adults with extreme shyness? A preliminary survey. Psychosom Med 52:517525

43. Gunnar MR, Connors J, Isensee J 1989 Lack of stability in neonatal adrenocortical reactivity because of rapid habituation of the adrenocortical response. Dev Psychobiol 22:321-333

44. Francis S, Walker R, Riad-Fahmy D, Hughes D, Murphy J, Gray O 1987 Assessment of adrenocortical activity in term newborn infants using salivary cortisol determinations. J Pediatr 111:129-133

45. Malone SM, Gunnar MR, Fisch RO 1985 Adrenocortical and behavioral responses to limb restraint in human neonates. Dev Psychobiol 18:435-446

46. Larson MC, Gunnar MR, Hertsgaard L 1991 The effects of morning naps, car trips, and maternal separation on adrenocortical activity in human infants. Child Dev 62:362-372

47. Gunnar MR, Larson MC, Hertsgaard L, Harris ML, Brodersen L 1992 The stressfulness of separation among nine-month-old infants: effects of social context variables and infant temperament. Child Dev 63:290-303

48. Gunnar MR, Hertsgaard L, Larson M, Rigatuso J 1992 Cortisol and behavioral responses to repeated stressors in the human newborn. Dev Psychobiol 24:487-505

49. Gunnar MR, Mangelsdorf S, Larson M, Hertsgaard L 1989 Attachment, temperament, and adrenocortical activity in infancy: a study of psychoendocrine regulation. Dev Psychol 25:355-363

50. Ramsay DS, Lewis M 1994 Developmental change in infant cortisol and behavioral response to inoculation. Child Dev 65:1491-1502

51. Lewis M, Ramsay DS, Kawakami K 1993 Differences between Japanese infants and Caucasian American infants in behavioral and cortisol response to inoculation. Child Dev 64:1722-1731

52. Lewis M, Thomas D 1990 Cortisol release in infants in response to inoculation. Child Dev 61:50-59

53. Gunnar MR 1986 Human developmental psychoneuroendocrinology: a review of research on neuroendocrine response to challenge and threat in infancy and childhood. In Lamb ME, Brown SL, Rogoff B (ed) Advances in Developmental Psychology. Erlbaum, Hillsdale, NJ

54. Fauci AS, Dale DC 1974 The effect of in vivo hydrocortisone on subpopulations of human lymphocytes. J Clin Invest 53:240-246

55. Meuleman J, Katz P 1985 The immunologic effects, kinetics, and use of glucocorticosteroids. Med Clin North Am 69:805-816 
56. Schleifer SJ, Scott B, Stein M, Keller SE 1986 Behavioral and developmental aspects of immunity. J Am Acad Child Psychiatry 26:751-63

57. Kaplan HB 1991 Social psychology of the immune system: A conceptual framework and review of the literature. Soc Sci Med 33:909-923

58. Ladd GW, Price JM 1987 Predicting children's social and school adjustment following the transition from preschool to kindergarten. Child Dev 58:1168-1189

59. Ladd GW 1990 Having friends, keeping friends, making friends, and being like by peers in the classroom: predictors of children's early school adjustment? Child De 61:1081-1100

60. Dingle JH, Badger GF, Jordan WS 1964 Illness in the Home: A Study of 25,000 Illnesses in a Group of Cleveland Families. Press of Western Reserve University, Cleveland

61. Magnano CL, Diamond EJ, Gardner JM 1989 Use of salivary cortisol measurements in young infants: a note of caution. Child Dev 60:1099-1101

62. Koskela M 1987 Serum antibodies to pneumococcal C polysaccharide in children: response to acute pneumococcal otitis media or to vaccination. J Pediatr Infect Dis 6:519-526

63. Caspi A, Moffitt TE 1991 Individual differences are accentuated during periods of social change: the sample case of girls at puberty. J Pers Soc Psychol 61:157-168

64. Bachen EA, Manuck SB, Marsland AL, Cohen S, Malkoff SB, Muldoon MF, Rabin BS 1992 Lymphocyte subset and cellular immune responses to a brief experimental stressor. Psychosom Med 54:673-679

65. Brosschot JF, Benschop RJ, Godaert GLR, Olff M, DeSmet M, Heijnen CJ, Ballieux RE 1994 Influence of life stress on immunological reactivity to mild psychological stress. Psychosom Med 56:216-224

66. Manuck SB, Cohen S, Rabin BS, Muldoon MF, Bachen EA 1991 Individual differences in cellular immune response to stress. Psychol Sci 2:111-115

67. Naliboff BD, Benton D, Solomon GF, Morley JE, Fahey JL, Bloom ET, Makinodan T, Gilmore SL 1991 Immunological changes in young and old adults during brie laboratory stress. Psychosom Med 53:121-132

68. Snyder BK, Roghmann KJ, Sigal LH 1993 Stress and psychosocial factors: Effects on primary cellular immune response. J Behav Med 16:143-161

69. Zakowski SG, McAllister CG, Deal M, Baum A 1992 Stress, reactivity, and immune function in healthy men. Health Psychol 11:223-232

70. Brodersen L, Rigatuso J, Gunnar M 1993 The effects of illness on infant salivary cortisol pretest levels: a methodological note. Society for Research in Child Development, New Orleans

71. Harbuz MS, Lightman SL 1992 Stress and the hypothalamo-pituitary-adrenal axis: Acute, chronic and immunological activation. J Endocrinol 134:327-339

72. Delbende C, Delarue C, Lefebvre H, Tranchand Bunel D, Szafarczyk A, Mocaër E, Kamoun A, Jégou S, Vaudry H 1992 Glucocorticoids, transmitters and stress. Br J Psychiatry 160:24-34
73. McEwen BS 1988 Steroid hormones and the brain: linking "nature" and "nurture." Neurochem Res 13:663-669

74. Meyer JS 1985 Biochemical effects of corticosteroids on neural tissues. Physiol Rev 65:946-1020

75. Fauci AS, Dale DC, Balow JE 1976 Glucocorticosteroid therapy: Mechanisms of action and clinical considerations. Ann Intern Med 84:304

76. Claman HN 1983 Glucocorticoids. I. Anti-inflammatory mechanisms. Hosp Pract $18: 123$

77. Munck A, Guyre PM, Holbrook NJ 1984 Physiological functions of glucocorticoids in stress and their relation to pharmacological actions. Endocrinol Rev 5:25-43

78. Ebert RH, Barclay WR 1952 Changes in connective tissue reaction induced by cortisone. Ann Intern Med 37:506

79. Daynes RA, Araneo BA 1989 Contrasting effects of glucocorticoids on the capacity of $T$ cells to produce the growth factors interleukin 2 and interleukin 4. Eur J Immunol 19:2319-2325

80. Robinson DS, Hamid Q, Ying S, Tsicopoulos A, Barkans J, Bentley AM, Corrigan C, Durham SR, Kay AB 1992 Predominant $T_{\mathrm{H} 2}$-like bronchoalveolar T-lymphocyte population in atopic asthma. N Engl J Med 326:298-304

81. Coe CL 1994 Implications of psychoneuroimmunology for allergy and asthma. In Middleton E (ed) Allergy: Principles and Practice. Mosby Yearbook, St. Louis

82. Maddan KS, Livnat S 1991 Catecholamine action and immunologic reactivity. In Ader R, Felten D, Cohen N (ed) Psychoneuroimmunology. Academic Press, San Diego

83. Shavit Y, Lewis JW, Terman GW 1984 Opioid peptides mediate the suppressive effect of stress on natural killer cell cytotoxicity. Science 223:188

84. Sapolsky R 1990 Adrenocortical function, social rank, and personality among wild baboons. Biol Psychiatry 28:862-885

85. Dahl RE, Siegel SF, Williamson DE, Lee PA, Perel J, Birmaher B, Ryan ND 1992 Corticotropin releasing hormone stimulation test and nocturnal cortisol levels in normal children. Pediatr Res 32:64-68

86. Meaney MJ, Aitken DH, Van Berkel C, Bhatnagar S, Sapolsky RM 1988 Effect of neonatal handling on age-related impairments associated with the hippocampus. Science 239:766-768

87. Price DA, Close GG, Fielding BA 1983 Age of appearance of circadian rhythm in salivary cortisol values in infancy. Arch Dis Child 58:454-456

88. Stanton ME, Patterson JM, Levine S 1985 Social influences on conditioned cortisol secretion in the squirrel monkey. Psychoneuroendocrinology 10:125-134

89. Coe CL 1993 Psychosocial factors and immunity in nonhuman primates: A review. Psychosom Med 55:298-308 